\title{
Основные методические подходы
}

\section{к организации учений специализированных противоэпидемических бригад Иркутского противочумного института}

\author{
A.K. Носков (noskov-epid@mail.ru), B.A. Вишняков, \\ М.В. Чеснокова, С.А. Косилко, С.А. Белькова, Л.М. Михайлов, С.В. Балахонов
}

\section{ФКУЗ «Иркутский научно-исследовательский противочумный институт» Роспотребнадзора}

\section{Резюме}

В статье отражены основные методические подходы к организации тренировочных учений специализированных противоэпидемических бригад в условиях, максимально приближенных к реальному экстраординарному событию, с целью поддержания оперативной готовности мобильных формирований Роспотребнадзора к работе в зоне чрезвычайной ситуации эпидемиологического характера.

Ключевые слова: специализированные противоэпидемические бригады, чрезвычайная ситуация, тренировочное учение

The Basic Methodical Approaches to the Organization of Trainings of the Specialized Anti-Epidemic Teams from Irkutsk Antiplague Institute

A.K. Noskov (noskov-epid@mail.ru), V.A. Vishnyakov, M.V. Chesnokova, S.A. Kosilko, S.A. Belkova, L.M. Mikhailov, S.V. Balakhonov1 Irkutsk Antiplague Research Institute of Federal Service for Surveillance on Consumer Rights Protection and Human Wellbeing

\section{Abstract}

The basic methodical approaches to the organization of trainings of the specialized anti-epidemic teams in the most approximate conditions to real extraordinary event are described. These trainings purpose the support of operative readiness of the mobile formations of Federal Service for Surveillance on Consumer Rights Protection and Human Wellbeing to work in an emergency epidemiological area

Key words: specialized anti-epidemic team, emergency situation, training

$\mathrm{H}$ аиболее масштабные чрезвычайные ситуации (ЧС) природного характера в новейшей истории России регистрировались на территории Сибирского и Дальневосточного федеральных округов. Среди них: сильнейшее землетрясение на о. Сахалин (1995 г.); серия наводнений в Республике Саха (Якутия), в Приморском крае, Иркутской области (2001 г.); катастрофические паводки на реке Амур (2013 г.) и в предгориях Алтая и Саян (2014 г.) [1]. В регионе регулярно регистрируются и ЧС, обусловленные инфекционными болезнями, представляющими опасность для населения. Так, вспышки сибирской язвы с общим числом заболевших 25 человек (из них 2 с летальным исходом) отмечены в Алтайском (2005, 2006, 2012 гг.) и Красноярском (2006 г.) краях, Республике Бурятия $(2007,2008)$ и Омской области (2010) [2]. В 2013 году на территории Ханты-Мансийского автономного округа зарегистрировано более 1000 случаев туляремии $[3,4]$. Сохраняется потенциальный риск возникновения ЧС эпидемиологического характера, обусловленных завозом на территорию Сибири и Дальнего Востока опасных инфекционных болезней из-за рубежа [5].
Для содействия учреждениям Роспотребнадзора, обеспечивающим санитарно-эпидемиологическое благополучие на пострадавших территориях региона, привлекаются специализированные противоэпидемические бригады Иркутского научно-исследовательского противочумного института (СПЭБ ИркутскНИПЧИ) [1, 6 - 8], входящие в Единую государственную систему предупреждения и ликвидации чрезвычайных ситуаций (РСЧС) как внештатные формирования. Организация работ в зоне ЧС в пределах ответственности СПЭБ ИркутскНИПЧИ проводится с учетом планового мониторинга актуальных эпидемиологических рисков, выявляемых с целью прогнозирования эпидемиологической обстановки $[9,10]$.

По результатам первого (2007 г.) и второго (2010 г.) этапов модернизации СПЭБ ИркутскНИПчИ сформированы мобильные лаборатории на базе пневмокаркасных модулей и автошасси, оснащенные высокотехнологичным лабораторным оборудованием. Приоритетной задачей СПЭБ остается обеспечение постоянной готовности к оперативному реагированию в случае возникновения ЧС, одним из инструментов поддержания которой являются учения. При проведении последних становится возможным от- 
работать алгоритмы действий в экстремальных ситуациях различного характера. Кроме того, учения позволяют выявить и устранить организационные и материально-технические недостатки, которые могут негативно повлиять на эффективность деятельности бригады в режиме ЧС.

Цель работы - обоснование и разработка методических основ организации оперативной готовности специализированных мобильных формирований Роспотребнадзора на основе анализа тренировочного учения СПЭБ ИркутскНИПЧИ (2014 г.).

При возникновении чС эпидемиологического характера специалисты СПЭБ должны оказывать квалифицированную практическую и консультативно-методическую помощь в организации и проведении противоэпидемических (профилактических) мероприятий и их лабораторном обеспечении.

В июне 2014 года проведено учение СПЭБ ИркутскНИПчИ "Ликвидация завозного очага чумы", в ходе которого отрабатывались практические навыки действий специалистов бригады в условиях, максимально приближенных к реальным. План учения включал три основных направления: первичные противоэпидемические мероприятия в месте выявления больного, противоэпидемический комплекс мероприятий, а также их лабораторно-диагностическое обеспечение.

При разработке легенды нами было акцентировано внимание на следующих важных аспектах: выборе нозологической формы (чума), места событий (изолятор противочумного института) и завозном характере эпидемического очага (реализация внешнего потенциального эпидемиологического риска).

Для чумы характерен ряд эпидемиологических особенностей, позволяющих обоснованно рассматривать данную нозологическую форму как универсальную модель инфекционной болезни, способной вызывать ЧС эпидемиологического характера: многообразие источников заражения человека, множественность механизмов и путей передачи, высокая восприимчивость, контагиозность в отдельных клинических формах и возможность быстрого распространения среди населения. Регистрация даже единичного случая чумы у человека (равно как и подозрения) требует экстренного проведения организационных, профилактических и противоэпидемических мероприятий, в том числе режимно-ограничительных или карантинных. Таким образом, условный эпидемический очаг чумы может рассматриваться как модель чС эпидемиологического характера для отработки практических навыков специалистов эпидемиологического и лабораторных подразделений СПЭБ.

Изолятор противочумного института имеет необходимый набор помещений для имитации обстоятельств выявления больного с подозрением на опасную инфекционную болезнь в условиях поликлиники, стационара, а также по месту жительства и отработки алгоритма первичных противоэпидемических мероприятий.
Завозной характер сформировавшегося эпидемического очага свидетельствует об экстраординарности события и определяет актуальность завоза чумы с эндемичных территорий как потенциального внешнего эпидемиологического риска. Вследствие этого учреждения Роспотребнадзора в рамках внутри- и межведомственного взаимодействия с заинтересованными подразделениями различных служб и ведомств должны обеспечить противоэпидемическую готовность к внезапному развитию событий в случае завоза опасных инфекционных болезней изза рубежа. Эффективность такого взаимодействия отрабатывается при привлечении - условно или по факту - территориальных учреждений Роспотребнадзора, здравоохранения, МчС России, пограничной, таможенной и других служб в зависимости от цели и задач учения.

По нашему мнению, особые требования должны предъявляться к разработке цели и задач учения. В рамках противоэпидемического комплекса мероприятий определяются конкретные задания для эпидемиологов и клиницистов. Для лабораторного обеспечения противоэпидемических мероприятий формулируются и практически отрабатываются алгоритмы индикации и идентификации возбудителей опасных инфекционных болезней в мобильных комплексах.

Согласно легенде учения, проведенного в 2014 году, в изоляторе противочумного института у одного из двух сотрудников научно-исследовательского учреждения Монголии, прибывших из г. Улан-Батора, выявлены клинические симптомы заболевания, не исключающие бубонную чуму.

В ходе занятия отрабатывался алгоритм действий персонала изолятора, членов оперативного штаба института, руководства СПЭБ и специалистов мобильных лабораторий. Основой принятия управленческих решений служил оперативный план института, разработанный на случай выявления больного с заболеванием, Вызванным ПБА I - II групп патогенности. При привлечении СПЭБ для осуществления мероприятий по обеспечению санитарно-эпидемиологического благополучия при ЧС деятельность бригады организуется в общей структуре противоэпидемических учреждений и направлена на решение задач, предусмотренных комплексным планом по санитарной охране территории субъекта РФ.

Несомненно, главным принципом недопущения распространения опасных инфекционных болезней среди восприимчивого населения является своевременное проведение первичных противоэпидемических (профилактических) мероприятий в месте выявления больного человека (подозрительного). В ходе учения необходимые в этих случаях практические навыки были отработаны сотрудниками изолятора: последовательно проведены мероприятия по локализации больного в месте выявления (врачебная), сбору клинико-эпидемиологических данных, передаче информации о событии, изоляции больного и контактировавших лиц в мельцеров- 
Рисунок 1.

Принципиальная схема организации первичных противоэпидемических (профилактических) мероприятий в случае выявления больного (подозрительного) с симптомами, не исключающими опасное инфекционное заболевание

Информирование о событии всех заинтересованных лиц, согласно схем оповещения;

Подготовка приказов по деятельности СПЭБ; Расчет потребности и обеспечение СПЭБ необходимым количеством расходных материалов, тест-систем, МИБП и пр.;

Обеспечение СПЭБ питанием и питьевой водой;

Подготовка и представление в Роспотребнадзор ежедневных донесений о работе СПЭБ;

Взаимодействие с органами исполнительной власти, участие в заседаниях комиссий, штабов
Выявление и изоляция больного; Отбор проб клинического материала; Изоляция контактировавших лиц; Медицинское наблюдение за контактировавшими; Проведение профилактического лечения; Соблюдение требований биологической безопасности

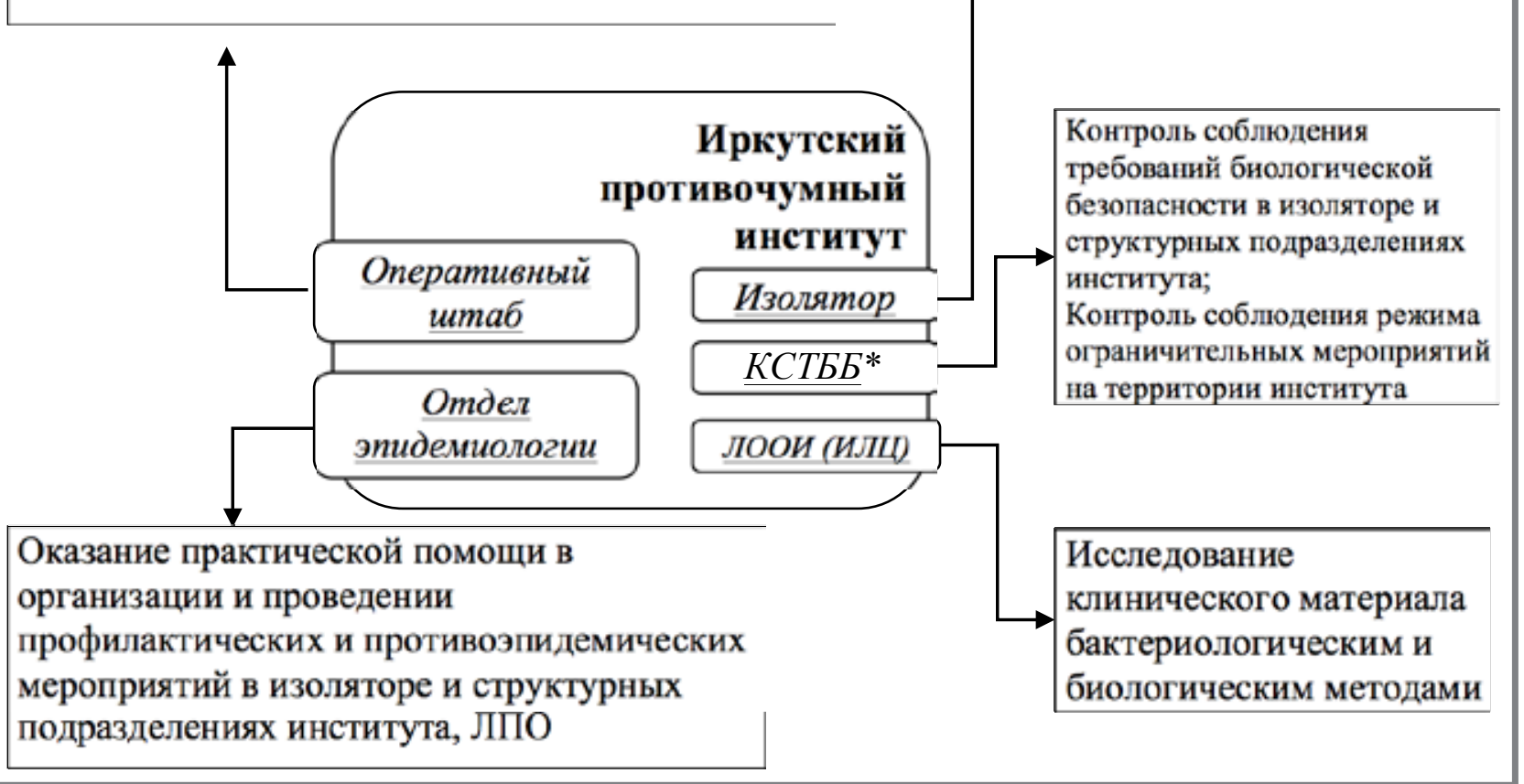

Примечание: *КСТББ - комиссия по соблюдению требований биологическиой безопасности.

ских боксах, проведению текущей дезинфекции, отбору проб клинического материала, подготовке их к транспортировке в лабораторию, эвакуации больного в специализированный инфекционный стационар, организации и проведению заключительной дезинфекции (рис. 1).

Оперативный штаб противочумного института, формирующего СПЭБ (далее - оперативный штаб), в каждой конкретной экстраординарной ситуации решает задачи, от которых зависит своевременность привлечения мобильных подразделений Роспотребнадзора в структуру противоэпидемических учреждений. Основными задачами оперативного штаба в условной ситуации являлись: выбор оптимального формата применения СПЭБ; разработка способов и маршрутов передислокации в зоне ЧС имущества и личного состава бригады; обеспечение как внутриведомственного, так и межведомственного взаимодействия при проведении противоэпидемических (профилактических) мероприятий; координация деятельности мобильного формирования в зависимо- сти от изменения эпидемиологической ситуации в зоне ЧС.

В условной ситуации специалистами оперативного штаба было принято решение о проведении индикации ПБА в мобильных комплексах (на автошасси), что позволило максимально приблизить лабораторную базу к условному эпидемическому очагу и тем самым сократить время доставки клинического материала, и об идентификации возбудителя в стационарных лабораториях испытательного лабораторного центра (ИЛЦ).

Данный тактический прием комплексного использования мобильных формирований и специализированных учреждений Роспотребнадзора, имеющих разрешение (лицензию) на деятельность с ПБА I-II групп патогенности, позволил рационально выстроить систему лабораторного обеспечения эпидемиологического расследования в условиях смоделированной ЧС.

Специалисты СПЭБ во взаимодействии с заинтересованными службами и ведомствами отра- 
ботали практические навыки в рамках алгоритмов мероприятий противоэпидемического комплекса и его лабораторного обеспечения (рис. 2).

В соответствии с целями учения проведено исследование пяти зашифрованных проб клинического материала. В индикационной лаборатории применены бактериоскопический (бактериоскопия мазков, окрашенных по Граму), молекулярно-генетический (ПЦР) и серологические (МФА, ИХТ, РНГА, РНАт) методы. В лаборатории особо опасных инфекций (ЛООИ) для выделения чистой культуры и постановки бактериологического диагноза использовали бактериоскопический, серологический, бактериологический и биологический методы. При исследовании клинического материала (мазки из зева, пунктат бубона) экспресс- и ускоренными методами (бактериоскопический, серологический, иммунофлюоресцентный) в течение трех часов был получен предварительный положительный на чуму результат. Молекулярно-генетическим методом (ПЦР в режиме реального времени) ДНК чумного микроба обнаружена через 5 часов 30 минут. По характеру роста на твердых и жидких питательных средах предварительный диагноз подтвержден через 18 часов, а чистая культура изолирована через 48 часов. Идентификация возбудителя завершена к концу четвертых суток. Установлено, что заболевание вызвано чум- ным микробом основного подвида Yersinia pestis subsp. pestis. Этиологическая расшифровка сформировавшегося эпидемического очага завершена через 96 часов от момента выявления больного.

Специалистами эпидемиологического отделения бригады на основании результатов лабораторного исследования и разработанного комплексного плана основных организационных, профилактических и противоэпидемических мероприятий при выявлении больного бубонной чумой практически отработаны алгоритмы действий в рамках эпидемиологического расследования, локализации и ликвидации условного эпидемического очага.

Таким образом, при организации учения в 2014 году применены основные методические подходы, позволяющие проводить плановую подготовку специалистов СПЭБ ИркутскНИПЧИ в условиях, максимально приближенных к реальным, что способствует повышению эффективности работы мобильного формирования в условиях чС. Научно обоснована разработка цели, задач и легенды учения, определены основные направления и алгоритмы действий специалистов СПЭБ ИркутскНИПчИ при проведении первичных противоэпидемических мероприятий в месте выявления больного, противоэпидемического комплекса и его лабораторного обеспечения.

\section{Литература}

1. Носков А.К., Шаракшанов М.Б., Вишняков В.А., Косилко С.А., Чеснокова М.В., Дугаржапова З.Ф. и др. Тактические приемы работы специализированных противоэпидемических бригад в различных чрезвычайных ситуациях на территории Сибири и Дальнего Востока. Дальневосточный журнал инфекционной патологии. 2014; 24: 20 - 24

2. Дугаржапова З.Ф., Чеснокова М.В., Кравец Е.В., Такайшвили В.Е., Иванова Т.А., Носков А.К. Чрезвычайные ситуации, связанные с эпизоотическими и эпидемическими проявлениями сибирской язвы в Сибири и на Дальнем Востоке (2004-2013 гг.). Дальневосточный журнал инфекционной патологии. 2014; $24: 101-104$.

3. Мещерякова И.С., Демидова Т.Н., Горшенко В.В., Добровольский А.А. Трансмиссивные эпидемические вспышки (групповые заболевания) туляремии в России в XXI веке. Дальневосточный журнал инфекционной патологии. 2014; 25: 53 - 55.

4. Попов В.П. Эпизоотическая ситуация во время вспышки туляремии в Ханты-Мансийском автономном округе (Югра) в 2013 году. Дальневосточный журнал инфекционной патологии. 2014; 25: 56 - 58.

5. Вишняков В.А., Носков А.К., Чеснокова М.В., Лапа С.Э., Дампилова И.Г. Транспортная инфраструктура как внешний риск формирования чрезвычайных ситуаций эпидемиологического характера в Забайкальском крае. Дальневосточный журнал инфекционной патологии. $2014 ; 24$ (24): 124 - 126.

6. Обеспечение санитарно-эпидемиологического благополучия населения при ликвидации последствий наводнения на Дальнем Востоке. Г.Г. Онищенко, С.В. Балахонова. ред. Новосибирск: Наука-Центр; 2014: 648

7. Онищенко Г.Г., Балахонов С.В., Носков А.К., Вишняков В.А., Косилко С.А., Чеснокова М.В. и др. Тактика применения специализированных противоэпидемических бригад в условиях крупномасштабного наводнения на Дальнем Востоке. Сообщение 1. Особенности деятельности мобильного формирования Роспотребнадзора в Амурской области. Проблемы особо опасных инфекций. 2014; $1: 7$ - 10.

8. Онищенко Г.Г., Балахонов С.В., Носков А.К., Вишняков В.А., Косилко С.А., Чеснокова М.В. и др. Тактика применения специализированных противоэпидемических бригад в условиях крупномасштабного наводнения на Дальнем Востоке. Сообщение 2. Особенности деятельности мобильных формирований Роспотребнадзора в Хабаровском крае, Еврейской автономной области. Проблемы особо опасных инфекций. $2014 ; 1: 11$ - 14.

9. Вишняков В.А., Носков А.К. Санитарная охрана территории субъекта Российской Федерации. Сообщение 1. Принципы дифференцированного подхода к организации мероприятий по санитарной охране территории на уровне муниципальных районов. Бюллетень Восточно-Сибирского научного центра CO PAMH. 2012; 5 (1): $360-362$.

10. Носков А.К., Вишняков В.А., Чеснокова М.В., Дмитриева Г.М., Дампилова И.Г., Зайцева Т.А. Опыт применения методики дифференциации муниципальных районов в различных субъектах Российской Федерации с целью систематизации эпидемиологических рисков проявления инфекционных болезней, представляющих опасность для населения. Биозащита и биобезопасность. 2014; 6 (1): 40 - 45.

\section{References}

1. Noskov A.K., Sharakshanov M.B., Vishnyakov V.A., Kosilko S.A., Chesnokova M.V., Dugarzhapova Z.F. et al. Balakhonov S.V. Tactical techniques of working of specialized antiepidmic teams in various emergency situations in Siberia and Far East territory. Far Eastern J. Infect. Pathology. $2014 ; 24: 20$ - 24 (in Russian).

2. Dugarzhapova Z.F., Chesnokova M.V., Kravets E.V., Takaishvili V.E., Ivanova T.A., Noskov A.K. Emergency situations associated with epizootic and epidemic anthrax manifestations in Siberia and at the Far East (2004-2013). Far Eastern J. Infect. Pathology. 2014; $24: 101$ - 104 (in Russian).

3. Meshcheryakova I.S., Demidova T.N., Gorshenko V.V., Dobrovolsky A.A. Transmissible epidemic outbreaks (group cases) of tularemia in Russia in XXI century. Far Eastern J. Infect. Pathology. 2014; 25: 53 - 55 (in Russian).

4. Popov V.P. Epizootic situation during a tularemia outbreak in Khanty-Mansiysk autonomous region (Yurga) in 2013. Far Eastern J. Infect. Pathology. 2014; 25: $56-58$ (in Russian)

5. Vishnyakov V.A., Noskov A.K., Chesnokova M.V., Lapa S.E., Dampilova I.G. Transport infrastructure as external risk of epidemiological emergency occurrences in Transbaikalian Territory. Far Eastern J. Infect. Pathology. 2014; 24 (24): 124 - 126 (in Russian).

6. Guaranteeing of sanitary-and-epidemiologic human well-being at elimination of the flooding consequences at the Far East. Eds., G.G. Onishchenko, S.V. Balakhonov. Novosibirsk: Science-Centre; 2014: 648 (in Russian).

7. Onishchenko G.G., Balakhonov S.V., Noskov A.K., Vishnyakov V.A., Kosilko S.A., Chesnokova M.V. et al. Tactics of application of the specialized anti-epidemic teams during large-scale flooding at the Far East. Report 1. Features of activities of the mobile formation of Rospotrebnadzor in the Amur region. Problems of Especially Dangerous Infections. 2014; 1: 7 - 10 (in Russian).

8. Onishchenko G.G., Balakhonov S.V., Noskov A.K., Vishnyakov V.A., Kosilko S.A., Chesnokova M.V. et al. Tactics of application of the specialized anti-epidemic teams during large-scale flooding at the Far East. Report 2. Features of activities of the mobile formations of Rospotrebnadzor in Khabarovsk Territory, the Jewish Autonomous Region. Problems of Especially Dangerous Infections. 2014; 1: 11 - 14 (in Russian). 
Рисунок 2.

Основные направления деятельности СпЭБ ИркутскНИПчИ в условном эпидемическом очаге бубонной чумы

Проведение эпидемиологического расследования, анализ и прогнозирование санитарно-

эпидемиологической обстановки;

Определение границ эпидемического очага. Выявление круга лиц, находившихся в

аналогичных по риску заражения условиях, контактировавших лиц и разработка

профилактических мероприятий;

Проведение эпидемиологического обследования места проживания (временного пребывания) больного и контактировавших лиц. Внесение обоснованных предложений в территориальное учреждение Роспотребнадзора о проведении в домашнем эпидемическом очаге заключительной дезинфекции (по показаниям - дезинсекции и дератизации);

Локализация эпидемического очага и проведение текущей дезинфекции;

Разработка и реализация экстренных противоэпидемических и профилактических мероприятий, проведение экстренной по эпидемиологическим показаниям неспецифической и специфической профилактики;

Участие в организации и контроль проведения дезинфекционных, дератизационных и дезинсекционных мероприятий;

Оказание консультативно-методической помощи в подготовке инфекционного госпиталя к приему больного бубонной чумой

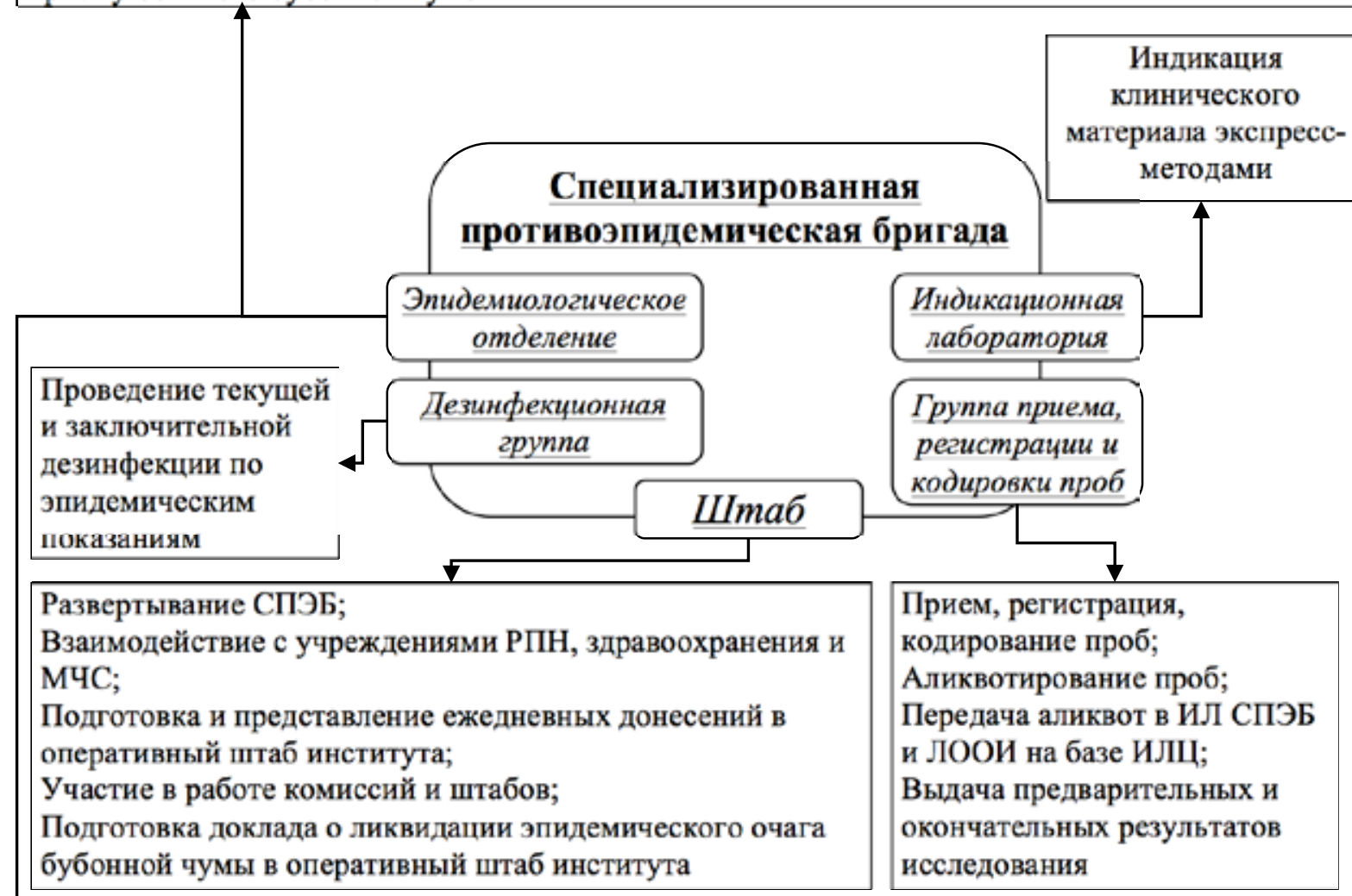

Инфекционный госпиталь (ОГБУЗ Иркутская областная инфекционная клиническая больница, г. Иркутск)

Изоляция и лечение больного бубонной чумой;

Отбор и транспортировка проб

клинического материала для

лабораторного исследования

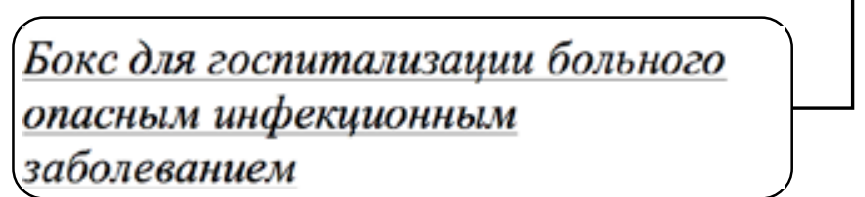

9. Vishnyakov V.A., Noskov A.K. Sanitary protection of territory of the Russian Federation Subject. Report 1. Principles of the differentiated approach to the organization of actions for sanitary protection of territory at the level of municipal areas. Bulletin of the East-Siberian Scientific Centre of Siberian Branch of the Russian Academy of Medical Science. 2012; 5 (1): 360 - 362 (in Russian).

10. Noskov A.K., Vishnyakov V.A., Chesnokova M.V., Dmitrieva G.M., Dampilova I.G., Zaitseva T.A. Experience of application of the differentiation technique for municipal areas in various Subjects of the Russian Federation for classification of epidemiological risks of infectious disease manifestations dangerous for humans. Bioprotection and Biosafety. 2014; 6 (1): 40 - 45 (in Russian). 